\title{
A PEDAGOGIA DO SOFRIMENTO EM UM ACAMPAMENTO BOMBEIRO MILITAR
}

\section{FÁBIO GOMES DE FRANÇA}

Pós-Doutor em Direitos Humanos, Doutor e Mestre em Sociologia pela Universidade Federal da Paraíba. Professor de criminologia e Sociologia do Centro de Educação da PMPB. Capitão da PMPB.

País: Brasil Estado: Paraíba Cidade: João Pessoa

E-mail: filhosdalegiao@gmail.com ORCID: https://orcid.org/0000-0003-1917-840X

\section{RESUMO}

Neste artigo, por meio de uma pesquisa qualitativa de cunho documental, analisamos os depoimentos testemunhais de alunos do Curso de Formação de Oficiais (CFO) do Corpo de Bombeiros Militar (CBM) da Paraíba acerca de um evento pedagógico conhecido na cultura militarista por acampamento. Os depoimentos colhidos fazem parte de um procedimento administrativo (Sindicância) realizado pelo CBM da Paraíba para apurar trotes que ocorreram durante o acampamento através de uma pedagogia do sofrimento imposta aos alunos. Em conclusão, destacamos o fato de como uma pedagogia militar aplicada a futuros profissionais em formação que desempenharão atividades de caráter civil demonstra ambiguidades quanto às suas finalidades, despertando-nos reflexões sobre a relação entre o respeito forçado à autoridade e a aprendizagem para o exercício de vidas a salvar.

Palavras-chave: Pedagogia do Sofrimento. Bombeiro Militar. Acampamento.

\section{ABSTRACT \\ THE PEDAGOGY OF SUFFERING IN THE FIREFIGHTER MILITARY CAMP}

The article aims to analyze a firefighter military camp as a pedagogical event of the military culture. We used a qualitative and documentary research through analysis of students' written testimonials of the Officer Training Course (OTC) in the Paraiba State, Brazil. The testimonials show abusive hazing took place at the military camp for firefighters students through pedagogy of suffering. In closing, we highlight that there are contradictions in this military pedagogy for firefighters students that will work developing civilian activities making us reflect on the relationship between the forced respect to the authority and the learning for profession.

Keywords: Pedagogy of suffering; military firefighter; camp.

Data de recebimento: 28/02/2021 - Data de aprovação: 19/07/2021

DOI: 10.31060/rbsp.2022.v16.n1.1438 


\section{INTRODUÇÃO}

A cultura diz respeito a um conjunto heterogêneo de elementos como símbolos, crenças, comportamentos, que demarcam características de um grupo, um povo, uma nação, e até mesmo uma instituição, de modo que as marcas culturais expostas pelos indivíduos, de certa forma, é o que revela sua presença em sociedade. No caso específico dos aspectos culturais de uma instituição passamos a falar de uma cultura organizacional. Assim, o que se torna alvo de nosso olhar e interpretação neste artigo é a cultura militar.

No caso do Brasil, a cultura militar, própria das Forças Armadas, torna-se extensiva às Polícias Militares (PMs) e aos CBMs estaduais devido à herança imposta a essas organizações por meio da Carta Constitucional de 1988 (aprovada após o regime político comandado pelos militares entre 1964-1985), que manteve em seu texto o fato das PMs e dos CBMs serem Forças auxiliares, reserva do Exército. Essa herança, que de maneira mais precisa remonta à criação das PMs e dos CBMs no Brasil, pode ser percebida, quanto às questões formais, em três vertentes centrais: instrução ou ensino profissional, Justiça Militar e regulamentos militares. Sobre o papel da cultura castrense própria dos quartéis, podemos perceber ainda sua presença com mais força e vigor nas relações informais, como os trotes durante a formação de alunos militares, além do sentimento de respeito apreendido em relação aos inúmeros símbolos como bandeiras, estandartes, fardamentos, hinos, patronos e comportamentos condicionados como a continência'. E mesmo que a Emenda Constitucional № 18 no Brasil tenha deixado clara certa divisão, sendo militares aqueles que pertencem às Forças Armadas e militares estaduais, os policiais e os bombeiros militares (BRASIL, 1998), ainda assim adotamos a perspectiva de que todas as instituições em conjunto envolvem seus profissionais em uma teia complexa de situações culturais comuns experienciadas pelos indivíduos que as constituem.

Essas experiências de contato com a cultura militar atingem certo ápice durante a formação profissional, pela qual os alunos militares (não importa se das Forças Armadas, das PMs ou dos CBMs) passam a conviver com um currículo formal (relacionado às disciplinas estudadas em salas de aula com viés teórico e as matérias de cunho prático) e outro informal ou oculto (que ocorre diariamente tanto dentro quanto fora das salas de aula, especialmente por meio das punições pelos desvios disciplinares cometidos contra as regras militares). Nesse processo, o currículo formal e o informal acabam confundindo-se em muitas situações e a naturalização dessa proximidade curricular cotidianamente vivenciada pelos alunos faz com que a autovigilância para evitar as punições disciplinares (FOUCAULT, 1987) desenvolva nos discentes militares a "disciplina consciente", jargão utilizado nas casernas para explicar a adequação do comportamento aos ditames das regras pedagógicas castrenses.

Só que a força da herança cultural do Exército nas PMs e nos CBMs demonstra um espírito de totalidade quando a busca pela disciplina consciente torna-se o vetor principal da formação dos alunos, de modo que, nos cursos militares, as tradições sobrepujam o papel profissional almejado. Melhor seria dizermos, quando falamos da formação militar para bombeiros militares (BMs) e policiais militares (PMs)², que

1 Segundo França (2020a, p. 24), a continência diz respeito ao "gesto utilizado pelos militares como forma de cumprimento e saudação entre eles e deles para com os símbolos reverenciados na cultura militar como a bandeira nacional, por exemplo. Caracteriza-se por um gesto feito com energia em um único tempo deixando o braço paralelo ao solo na mesma altura do ombro e o antebraço em um ângulo de 45 graus em relação ao braço com a palma da mão estendida para baixo, dedos das mãos unidos numa postura rija e estes últimos tocando ligeiramente a fronte na altura da testa".

2 Percebam que no caso das Polícias Militares podemos utilizar a mesma sigla tanto para se referir à instituição quanto aos seus profissionais, de modo que o entendimento depende do contexto no qual a sigla está sendo empregada. 
eles se tratam de militares bombeiros ou militares policiais, invertendo a lógica da denominação que os caracteriza. A formação militar nas casernas das Forças estaduais enaltece o ideal bélico criando, $a$ posteriori, dilemas em relação aos novos papéis que devem ser desempenhados no exercício da profissão, no contato com a sociedade, o que reconhecemos ser um conflito entre "a caserna e a rua" (SILVA, 2011).

Entre as tradições militares copiadas do Exército pelas PMs e pelos CBMs temos os acampamentos militares. Esses acampamentos consistem em momentos nos quais as aulas formais são suspensas para que os alunos permaneçam em curtos períodos de tensão física e psicológica extrema (geralmente de 1 semana), sob a tutela de uma coordenação pedagógica, para testar a capacidade de resistência à obediência à autoridade e aos limites impostos ao corpo e à mente. São testes de sobrevivência que têm origem nas Forças Armadas, as quais simulam situações de guerra para que os alunos tenham uma noção do que pode ocorrer em uma guerra real na qual os recursos ficarão escassos e o trabalho em equipe será fundamental para que todos sobrevivam. Geralmente esses testes de sobrevivência ocorrem em regiões de mata fechada, próximas a rios ou represas, para que os alunos, trabalhando em equipe, aprendam como obter recursos naturais para sobreviver.

É uma dessas experiências de um acampamento militar com alunos bombeiros que passamos a descrever adiante a partir dos relatos dos próprios estudantes que nos forneceram cópias de seus depoimentos em uma sindicância na qual foram testemunhas dos excessos praticados pelos Oficiais ${ }^{3}$ que estavam à frente do treinamento. Os fatos ocorreram em 2018 durante um acampamento com alunos do CFO para BMs na Paraíba.

\section{O "CURRÍCULO DA SELVA"}

Não existem escritos sobre experiências de acampamento militar entre alunos BMs no Brasil, isso porque até aqui parece-nos que o campo acadêmico não despertou para os estudos sobre a relação entre os BMs e a vida castrense e suas regras, o que nos faz levantar a hipótese de que essa lacuna talvez permaneça devido à imagem social positiva atrelada à profissão bombeiro militar em nosso país. Recentemente, em um estudo inédito realizado por França (2018), por meio de dados colhidos em portais eletrônicos, encontramos a análise de uma série de mortes de alunos BMs durante a formação profissional em vários lugares do Brasil. A pesquisa se debruçou sobre as consequências negativas advindas dos trotes militares durante aulas de salvamento aquático com alunos BMs. Com o mesmo escopo, França e Ribeiro (2019) analisaram a morte de um aluno soldado BM, ocorrida em 2016, a qual pode ter sido consequência do 'caldo'4 sofrido por ele em uma instrução de salvamento aquático. Até a escritura deste texto, a batalha judicial pela incriminação de uma tenente do CBM do Mato Grosso, que é a principal acusada da prática de tortura pela aplicação do caldo ao aluno, está em trâmite na justiça (FERNANDES, 2020).

A busca pelo limite físico e psicológico é a tônica reinante em cursos e acampamentos militares que isolam indivíduos em ambientes inóspitos para o homem com o intuito de testar sua capacidade de reação ao que

3 O modelo hierárquico das PMs e dos BMs é uma cópia do modelo organizacional do Exército que consiste em dois quadros distintos: o das Praças (soldado, cabo, terceiro-sargento, segundo-sargento, primeiro-sargento e subtenente) e o dos Oficiais (segundo-tenente, primeirotenente, capitão, major, tenente-coronel e coronel). Ao primeiro, em tese, cabem as funções de execução e, ao segundo, as funções de comando, gestão e fiscalização.

$4 \quad$ O caldo é uma espécie de trote utilizado pelos BMs em aulas de natação e salvamento aquático, no qual o(a) aluno(a) é literalmente afogado(a), tendo sua cabeça forçadamente submergida por meio de outra pessoa. O caldo funciona na cultura bombeirística como adaptação do sofrimento impingido a alunos militares em cursos nas Forças Armadas. 
poderá ser encontrado como dificuldade nas diversas situações da profissão. Não existem comprovações técnicas ou científicas que ratifiquem essas crenças, pelo contrário, o que os estudos sobre o tema têm demonstrado é que esses treinamentos desencadeiam um tipo de socialização que faz os alunos militares internalizarem aspectos como rusticidade, virilidade e um ethos bélico ou guerreiro que ao mesmo tempo potencializa o machismo e a masculinidade (HUGGINS; HARITOS-FATOUROS; ZIMBARDO, 2006).

A herança da violência institucional contra alunos militares em trotes e treinamentos faz parte de um conjunto de tradições que eram pautadas em formas de punição física contra as Praças por parte dos Oficiais tanto no Exército como na Marinha (FRANÇA, 2018). As PMs acompanharam esse caminho e não poderia deixar de ser diferente com os CBMs, que por muito tempo estiveram subordinados institucionalmente às PMs. Por mais que formalmente os castigos físicos tenham sido proibidos, ainda assim, processos culturais, para serem desconstruídos, demandam várias gerações (ELIAS, 1994), o que não foi o caso da violência institucional entre os militares que se adaptou a outras situações, entre as quais os acampamentos. A longevidade desses processos de violência, o que indica a persistência de fenômenos culturais tão marcantes, pode ser percebida historicamente entre os militares franceses desde o Antigo Regime até a formatação de um Exército moderno, com mais notoriedade a partir do século XIX, onde o ensino da violência consiste em que

Os antigos praticam sobre os recrutas a pedagogia da violência. Ela é feita de troças que, começando pela feira de animais, rebaixam os recrutas à condição de animais. Depois, o conscrito é submetido à coberta, quando seu corpo é lançado no ar em uma coberta cheia de objetos cortantes. A instrução militar se dá, com efeito, muitas vezes, sob o temor permanente da punição e em meio a gritos, insultos e golpes. A despeito das denúncias feitas pelos médicos do efeito dos maus-tratos infligidos sobre os soldados por suboficiais violentos, vis, caprichosos e, algumas vezes, perversos, o tempo do exercício continua sendo, geralmente, o da brutalidade. A força e resistência ao cansaço, a aptidão para superar o sofrimento físico e a dor moral, enfim, a aceitação de derramar seu sangue para a defesa do país são um conjunto de qualidades viris que encontram sua completa satisfação no estado militar. Ao aceitar sofrer a violência dos antigos, sem ficar muito zangado, o conscrito se integra em um grupo dentro do qual ele talvez seja chamado para o combate (BERTAUD, 2013, p. 74-82, grifos do autor).

Essa "pedagogia da violência" ou "pedagogia do sofrimento" (FRANÇA; GOMES, 2015) torna-se o portão de entrada dos iniciados alunos militares de modo geral ao mundo real das práticas bélicas de morte quando forem chamados para o combate. A morte deve ser naturalizada para evitar-se a covardia e a desonra diante do sofrimento de corpos que caem tombados pelo fogo cuspido do cano dos fuzis, das metralhadoras e pistolas. Para esse enfrentamento, o sofrimento deve ser o ensinamento ao próprio corpo para que a mente entenda que, para que o corpo a sustente, este deve doar-se em sacrifício, não como um exercício definitivo de resignação, mas como um ato de heroísmo, pois a honra surge como um componente simbólico necessário de adequação de corpos que aceitam a morte como o triunfo final, já que foram antes exercitados para tal fim.

Não temos condições de precisar historicamente como essa herança cultural dos Exércitos europeus chegou até nós, mas acreditamos que no caso do Brasil não podemos falar de uma transposição unilateral apenas do legado português ao modo como nossas Forças Armadas, PMs e CBMs desenvolveram seus modelos culturais intra corporis. Não podemos esquecer que no início do século XX uma missão composta por oficiais militares do Exército brasileiro foi à Alemanha, os quais ficaram conhecidos como jovens turcos, onde estagiaram para aprender as formas de organização do Exército alemão. Esses Oficiais 
depois se engajaram na reformulação do ensino militar no Exército com o intuito de profissionalizar seus homens pela perspectiva das doutrinas castrenses para afastá-los do ativismo político recorrente na República Velha (MARQUES, 2014). Outro fato foi a vinda da Missão Militar Francesa para reorganizar a então Força Pública de São Paulo (depois Polícia Militar) em 1906 até 1914, com retorno após a Primeira Grande Guerra e a partir de 1919 no Exército brasileiro, ficando até 1940 (FERNANDES, 1973).

A Missão Militar Francesa deixou um legado de organização institucional que, provavelmente, se estende dos tipos de treinamento ao campo das práticas culturais. Tanto que foi o modelo de Educação Física trazido pelos militares franceses que passou a ser adotado no Exército brasileiro a partir de 1921, chegando até mesmo a ser aplicado em todo o território nacional pelas escolas públicas federais e municipais e pelas escolas privadas, devido à influência do Exército no país durante o Estado novo varguista (CASTRO, 1997). Sem contar que as técnicas de tortura utilizadas durante o regime ditatorial em nosso país pelos militares teve forte influência dos militares franceses de alta patente que aqui estiveram para ministrar cursos de contra-guerrilha, já que eles tinham utilizado essas técnicas durante a Guerra de Libertação da Argélia, que era colônia francesa (DUARTE-PLON, 2016).

No Brasil, um estudo inédito realizado por Huggins, Haritos-Fatouros e Zimbardo (2006) sobre a formação PM durante o período ditatorial destaca como a lógica da repressão governamental precisava treinar os PMs com base no sofrimento para que eles reproduzissem a mesma disposição quando fossem atuar nas ruas. A crença generalizada entre os militares, incluindo os policiais, da existência de um inimigo interno (os subversivos comunistas) que impulsionava a defesa da "ideologia da segurança nacional" fazia do treinamento dos PMs primeiramente uma busca pela obediência cega à autoridade. A perspectiva ideológica da luta contra o comunismo atrelava-se naturalmente ao modo de atuação violento próprio dos PMs, que deveriam treinar e sofrer arduamente para enfrentar um inimigo do Estado e da sociedade democrática em perigo, desde que fossem homens obedientes. Os trotes eram utilizados (na verdade, ainda hoje o são) ${ }^{5}$ como expediente recorrente na formação dos PMs e o currículo oculto passava a operar desde a chegada dos alunos para o início do curso de formação, modelo pedagógico que era estritamente copiado do Exército (CASTRO, 2004).

O que estava em jogo era um modelo de conduta que passava a ser esperado dos PMs depois de formados, como fruto de forças situacionais modeladoras do caráter de indivíduos que foram colocados à prova em situações de estresse extremo, o que não deixa de ser um treinamento de torturadores, já que são processos de socialização que nos ensinam a reproduzir violentamente o que aprendemos do mesmo modo (ALMEIDA JÚNIOR, 2016; FRANÇA, 2020b). Nesse contexto, os PMs se transformavam em "operários da violência" (HUGGINS; HARITOS-FATOUROS; ZIMBARDO, 2006).

Ao entrevistar PMs que participaram da formação pedagógica militar durante o período ditatorial e sem encontrar fatores diretos que pudessem apontá-los como indivíduos violentos antes de ingressarem na PM, Huggins, Haritos-Fatouros e Zimbardo (2006) demonstram que os alunos PM novatos chegavam ao quartel em cima de um caminhão, sendo transportados sem nenhum conforto, como animais, já que se tratava de uma tropa. As boas-vindas eram feitas por um Oficial que, aos gritos, destratava a todos pela aparência suja e pela ausência de disciplina militar ${ }^{6}$. A partir daí, a nova rotina passava a ser experienciada,

5 Ver Albuquerque e Machado (2001a; 2001b; 2003); Alvito (2013); França (2013) e Leal (2011).

6 A mesma forma de tratamento aos insultos e gritos foi descrita em livro por um jornalista que fez o concurso para soldado da PM do Rio de Janeiro em 2007 apenas para acompanhar as semanas iniciais do curso e entender melhor como ocorre esse processo de socialização profissional. Ver Gomide (2018). 
inicialmente com o corte de cabelo no estilo militar, com a adoção de um nome de guerra, bem como, de um número (GOFFMAN, 2007) que passava a identificar a todos:

Não sendo mais identificado como o homem que fora e, a partir de então, como um "guerreiro" que tinha um "nome de guerra" e um número que ocultavam sua identidade, a verdadeira identidade do treinando fora separada de seu status civil e estava então madura para ser remodelada como uma identidade inteiramente militarizada (HUGGINS; HARITOS-FATOUROS; ZIMBARDO, 2006, p. 275, grifos dos autores).

Ainda relatam Huggins, Haritos-Fatouros e Zimbardo (2006) que essa ruptura com a antiga vida civil, que funciona como uma "mortificação do eu" ou uma "morte civil" (GOFFMAN, 2007, p. 24-25), descortinavase entre a aprendizagem das marchas militares e a extenuante jornada de treinamento que se iniciava às 4 h30 da madrugada e se estendia até às $18 \mathrm{~h}$. Os alunos em formação passavam por situações desde ter que se aprontar em dois minutos para se vestir impecavelmente e entrar em forma ${ }^{7}$ a serem acordados com gás lacrimogêneo no alojamento. Não obstante, entre atividades práticas e teóricas, mas especialmente pela convivência com o currículo oculto, que obrigava os alunos a vivenciarem constantemente o exercício da obediência para com os superiores (que se mostravam com a face rígida e jeito de "macho" para impor autoridade), as palavras de um entrevistado sintetizam que no treinamento: "eram obrigados a rolar no mato, por cima de espinhos, paus, pedras, como se fossem porcos (...) [Se] se ferisse o instrutor achava muito divertido. Ele treinava o policial para ir à guerra, não para proteger o povo. Jogavam bombas de gás dentro da sala de aula" (HUGGINS; HARITOS-FATOUROS; ZIMBARDO, 2006, p. 278).

As inumeráveis formas de fazer o currículo oculto funcionar ainda sustentava-se por situações violentas como o corredor polonês, no qual o aluno PM passava no meio de duas fileiras de colegas e era atingido por socos e pontapés, como recorda um dos entrevistados: "Eu me lembro de ter levado um murro no estômago - não sei se foi um soco ou um pontapé. Só sei que caí no chão desmaiado" (Ibid., p. 285).

Essa mesma lógica de uma pedagogia violenta aplicada a alunos militares de modo geral presente nos treinamentos e na execução dos trotes também é a mesma utilizada nos acampamentos militares, que é um misto de trotes com atividades e treinamentos de sobrevivência na selva. No Brasil, as únicas informações que temos sobre acampamentos militares dizem respeito a um trabalho de campo (ALBUQUERQUE, 1999; ALBUQUERQUE; MACHADO, 2001a, 2001b) realizado sobre a Jornada de Instrução Militar (JIM) aplicada a alunos oficiais da PM da Bahia em 1997, mas em contato pessoal com um tenente recém formado no CFO da Bahia em 2017, constatamos que a JIM ainda ocorre nos mesmos moldes de décadas atrás8.

Como não poderia deixar de ser, a análise sobre a realização da JIM no CFO da Bahia revela aspectos contraditórios do ensino PM após a abertura política com o fim do regime ditatorial. Paralelo à chegada de disciplinas humanísticas nas Academias de Polícia Militar, com os Direitos Humanos como carro-chefe, os trotes e os acampamentos militares permanecem sendo utilizados por meio de um currículo cultural (LEAL, 2011) e oculto que atua impondo resistências a um ensino com viés democrático, por meio do qual os próprios alunos militares deveriam ser respeitados em suas integridades física e psicológica.

O que a JIM demonstrou foi a realização de atividades próprias de sobrevivência em uma guerra em um verdadeiro "currículo da selva" (ALBUQUERQUE; MACHADO, 2001a), já que foi realizada em um trecho de

7 Entrar em forma é o ato em que todos os alunos ficam colocados um atrás do outro em colunas e linhas, geralmente estáticos na posição de sentido ou de descansar, formando uma figura retangular, por meio de certa padronização espacial. Ver França (2019).

8 Informação oral. 
mata atlântica pertencente ao Exército, durante um período de seis dias. Em síntese, na JIM conjugaramse "a um só tempo, técnicas de sobrevivência na selva com velhos ensinamentos anti-guerrilha num ritmo estressante, baseado em táticas que estimulam a ansiedade e o medo, produzindo um estado psicológico de absoluta (sic) alerta emocional" (ALBUQUERQUE; MACHADO, 2001a, p. 11). O sigilo sobre as atividades e as narrativas das edições passadas circundam e aumentam ainda mais a ansiedade dos cadetes $^{9}$, pois o local de realização desses eventos não é revelado aos alunos pela equipe organizadora, fazendo da surpresa sobre o que se pode encontrar um componente da pressão psicológica. Assim, a JIM tem início "com a partida de ônibus da Academia rumo ao local da jornada, numa viagem estressante, de quase uma hora, com simulações de ataques e bombas de gás. Após a chegada e concentração de todos para apresentação aos superiores são repassadas as regras que vigorarão naqueles dias" (Ibid., p. 11). A estrutura militar do acampamento se revela desde o início, de modo que

\begin{abstract}
A tarefa imediata, ao chegar, é a preparação do acampamento (barracas, cozinhas, sanitários, etc.) e o reconhecimento do território com uma pequena marcha. Pelas manhãs, depois do despertar, passamse instruções específicas sobre as atividades do dia e, a seguir, toma-se um breve café. Os intervalos para refeição, descanso e asseio pessoal dependem da dinâmica do dia. Conforme as atividades, os dias podem ser divididos em: dias de provas e jogos militares, onde o candidato deverá ultrapassar a si mesmo, superando seus limites, mostrando coragem e espírito de grupo (ALBUQUERQUE, MACHADO, 2001a, p. 11).
\end{abstract}

Mas são as palavras dos próprios alunos que participaram da JIM que se tornam interessantes para compreendermos a dinâmica das subjetividades envolvidas no acampamento, bem como o ideal coletivo almejado de fortalecimento do espírito de corpo e solidariedade grupal. No entanto, essas condições ocultam, na realidade, o objetivo principal da JIM: a obediência estrita à autoridade por meio da resignação e do sofrimento. Não por acaso, alguns alunos destacarem os princípios militaristas da JIM: "Essa mania de misturar as coisas das forças armadas com as da polícia enche o saco... a gente fica perdendo tempo no mato, tomando porrada e morrendo de fome" (ALBUQUERQUE; MACHADO, 2001a, p. 13).

Sabendo que, no Brasil, especialmente durante o período ditatorial, era comum PMs exercerem o serviço de BMs e vice-versa, como parte de uma transição fluida entre as instituições, além também de ser comum que os BMs fossem treinados nos quartéis de polícia militar (FRANÇA, 2018), fica-nos a reflexão de que em grande medida os treinamentos militares empregados aos alunos BM foram os mesmos ou talvez apresentassem algumas adaptações em relação aos que eram aplicados aos alunos PM. A demonstração dessa hipótese se fortalece exatamente no caso que descrevemos abaixo, de um acampamento militar do qual participaram alunos oficiais bombeiros do CFO na Paraíba.

\title{
EXPERIÊNCIAS DE UM ACAMPAMENTO MILITAR PARA BOMBEIROS
}

O CFO para BMs, na Paraíba, tem como forma de ingresso o Exame Nacional do Ensino Médio (ENEM), e tem um período de duração de três anos, tratando-se de um bacharelado em Engenharia de Segurança contra Incêndio e Pânico. O curso ocorre na Academia de Bombeiro Militar Aristarcho Pessoa, a qual funciona no mesmo espaço arquitetônico onde acontece o CFO para os alunos oficiais da PM, ou seja, no Centro de Educação da Polícia Militar do Estado da Paraíba, localizado na cidade de João Pessoa. Nesse sentido, os

9 Expressão dos quartéis das Forças Armadas, das PMs e dos CBMs para nomear os alunos oficiais. 
cadetes, como são conhecidos os alunos oficiais PM e BM, mesmo não dividindo as salas de aula, por se tratarem de cursos distintos, em contrapartida dividem alojamentos por ano de curso, de forma separada para homens e mulheres, participam conjuntamente das formaturas gerais (que são solenidades típicas dos quartéis com a leitura das ordens do dia, o cântico do hino nacional e o desfile da tropa), e assumem algumas funções comuns a uma caserna militar, como plantões de alojamento e adjunto e cadete de dia. Estas funções informam certo grau de responsabilidade por parte dos cadetes escalados para exercê-las, visto que eles passam gradativamente ao longo dos três anos a desempenhar papéis que lhes ensinam a externar certa autoridade dentro do quartel de formação, especialmente em relação aos demais alunos.

Por isso falamos nos cursos militares de alunos veteranos e alunos novatos, cabendo aos primeiros (no caso os do último ano da formação) geralmente a aplicação dos trotes aos ingressantes no CFO nas semanas iniciais de adaptação e acampamentos militares. No transcorrer das atividades cotidianas, gradativamente de acordo com a sequência dos anos de curso $\left(1^{\circ}, 2^{\circ}\right.$ e $\left.3^{\circ}\right)$, os alunos do $1^{\circ}$ ano se reportam aos do $2^{\circ} \mathrm{e}$ $3^{\circ}$ pela deferência de senhor ou senhora, assim como os do $2^{\circ}$ ano aos do $3^{\circ}$ do mesmo modo (FRANÇA, 2012). Ainda mais, com a alternância das turmas a cada ano, já que enquanto uma se forma outra ingressa; os cadetes também passam a se tratar como "antigos" e "modernos", de modo que o aluno se torna mais antigo com o avanço aos anos posteriores do curso desde a entrada no CFO (o aluno do $3^{\circ}$ ano é mais antigo que o do $2^{\circ}$ e do $1^{\circ}$, enquanto que o do $2^{\circ}$ ano é mais antigo que o do $1^{\circ}$ ), assim como as turmas também se tornam mais antigas e modernas entre elas mesmas, o que se estende posteriormente após os

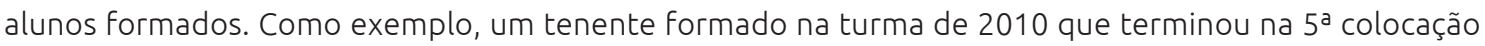
geral é mais antigo que os demais componentes de sua turma a partir da $6^{a}$ colocação, assim como todos da turma de 2010 são mais antigos do que todos que se formaram na turma de 2011.

Quando os alunos passam do $1^{\circ}$ ano ao $2^{\circ}$, do $2^{\circ}$ ao $3^{\circ}$, ou ainda quando saem formados como aspirantes a oficial para o estágio probatório que os habilitarão ao posto de $2^{\circ}$ tenente carregam consigo a classificação geral obtida com a média final do somatório das disciplinas estudadas a cada ano, a qual define antiguidade e modernidade separadamente por ano. Quanto maiores as médias, mais antigos na classificação, com o adendo da denominação pejorativa de alunos da "rabada", aqueles que assumem as últimas posições na hierarquia das médias, e alunos da "zerada", aqueles que são considerados mais estudiosos, o que se torna o indicativo de como funciona antiguidade e modernidade dentro das próprias turmas de formação (FRANÇA, 2012). O destaque fica por conta da emblemática figura do 01 (zeroum), que indica uma posição de prestígio (LEIRNER, 1997), que pode ser o primeiro colocado quando do ingresso no $1^{\circ}$ ano com a média do ENEM, durante o $2^{\circ}$ e $03^{\circ}$ ano a partir da classificação final obtida no ano anterior, ou por meio da ordem classificatória ao término do curso.

Outro critério para demarcar "antigos" e "modernos" é a classificação verticalizada no $1^{\circ}$ ano pela nota obtida no ENEM (CASTRO, 2004) quando do ingresso no CFO, a partir da qual o 01 (zero-um), primeiro colocado, é mais antigo que o 02 (zero-dois), segundo colocado, seguindo-se os demais. Ainda se demarca antiguidade e modernidade pela data de fundação da Academia Militar estadual a que se pertence (mais antiga é a que primeiro foi fundada), ou ainda considera-se mais antigos os alunos da Academia sede do curso, seguindo-se os alunos das Academias de outros estados que enviam seus alunos por não possuírem local de formação próprio, os quais são conhecidos por "estrangeiros". Nesse sentido, antiguidade e modernidade "são posições que servem para elencar responsabilidades e privilégios entre os cadetes, tanto no que se refere às regras prescritas como às situações informais do cotidiano. Por isto, quanto mais antigo na formação supõe-se ser melhor, obtendo-se mais reconhecimento e status" (FRANÇA, 2019, p. 367). 
Na verdade, os critérios de antiguidade e modernidade são sintomáticos para nos mostrar a importância do papel da autoridade no meio militar e sua tradução através da hierarquia, havendo impossibilidade de dois indivíduos ocuparem a mesma posição hierárquica, pois sempre algum atributo será mobilizado para legitimar a antiguidade. A partir da complexidade que envolve essas gradações hierárquicas e da necessidade que se cria para se exigir respeito por parte do subordinado em relação à autoridade que representa a figura do superior ou da superiora hierárquica na cultura militar é que podemos compreender como os momentos de sofrimento impingidos aos alunos acabam se naturalizando. Isso porque o sofrimento em conjunto os ensina que esse direito adquirido de exercer autoridade surgiu pelo compartilhamento de experiências traumáticas que os possibilitaram aprender a comandar homens em uma rede hierárquica complexa, já que existia uma razão para as humilhações verbais e as dores físicas: "Cadetes! Ides comandar, aprendei a obedecer" (CASTRO, 2004, p. 22). Por meio de um rito de passagem (VAN GENNEP, 2011) que denota um processo ritual de rebaixamento e elevação de status (TURNER, 2013), os cadetes encontram nos acampamentos militares momentos oportunos de experienciarem as ambivalências de um modelo de hierarquia e autoridade que ao mesmo tempo em que rebaixa o indivíduo pela humilhação o enaltece por ter aceitado compreender a lógica do respeito pela resignação.

No caso específico do acampamento militar com bombeiros paraibanos, a turma de cadetes protagonistas do evento ingressou no CFO em 2018, de modo que o acampamento ocorreu durante o segundo ano de formação, em 2019. A turma é composta por 29 alunos no total, sendo 25 homens e 4 mulheres. Na composição da turma, temos 8 cadetes da Paraíba (sendo 5 homens e 3 mulheres), 12 cadetes do Rio Grande do Norte (sendo 1 mulher) e 9 cadetes de Alagoas (todos homens).

Os relatos colhidos e analisados neste tópico foram obtidos dos depoimentos de quatro desses alunos, todos do gênero masculino. O acampamento militar ocorreu na cidade de Pedras de Fogo, na Paraíba. Houve certo receio dos alunos com o que seria feito com seus depoimentos nesta pesquisa, mas ficou claro para todos que os relatos seriam transformados em material analítico para a escritura de um artigo sobre a pedagogia do sofrimento na formação bombeiro militar. Além disso, o texto foi repassado a todos os alunos antes de ser definitivamente enviado para publicação, e seus nomes foram preservados, sendo utilizados pseudônimos. O acampamento foi dirigido pelos Oficiais da Academia Aristarcho Pessoa e pelos alunos do $3^{\circ}$ ano (os alunos veteranos) do CFO BM.

Segundo os depoimentos, as atividades prévias de preparação para o deslocamento ao acampamento ocorreram ainda no Centro de Educação, por volta da 1h da madrugada do dia 8 para o dia 9 de agosto de 2018, quando os alunos do $1^{\circ}$ ano do CFO BM, que ainda estavam em internato escolar, foram acordados pelos cadetes do $3^{\circ}$ ano recebendo a ordem de se vestirem com o "uniforme de instrução" em cinco minutos para depois se deslocarem à sala de aula. Ainda era preciso que os cadetes reunissem todo o material necessário, pois eles participariam de uma atividade externa, a qual não foi revelada. Essa primeira etapa ocorreu sob a presença de um tenente coordenador disciplinar do CFO. No conjunto, nem todos os cadetes se preocuparam em pegar coisas básicas, como material de higiene, incluída lâmina de barbear por parte dos homens, de modo que, já durante o acampamento, "foi enfatizado (pelos instrutores) que a ausência de informação quanto aos materiais que cada cadete deveria levar consigo era proposital para fins de verificação de tirocínio de cada componente da turma" (Aluno 2). Percebemos que o sigilo (ALBUQUERQUE; MACHADO, 2001a) utilizado comumente nesse tipo de atividade militar passou a ser usado desde o início, pois a ideia do "tirocínio", que seria uma espécie de aprendizado pela experiência, foi usado pelos coordenadores como argumento sem nenhum critério técnico, por pura dedução de "senso comum". 
Depois que os cadetes foram embarcados no ônibus, seguiram com destino ao acampamento por cerca de 30 a 40 minutos, mas precisaram desembarcar antes do local final, onde encontraram um major, uma capitã e outro tenente, além dos que já os acompanhavam, os quais compunham os oficiais da coordenação. A partir daí, os cadetes realizaram uma marcha por uma estrada de barro até chegar ao local onde seria montado o acampamento. Nessa marcha, "foram recolhidos os relógios dos cadetes; após chegarem ao acampamento foi realizada uma revista na bolsa de todos os integrantes da turma, sendo recolhido todos os alimentos" (Aluno 1). Foi depois da chegada da marcha que os alunos souberam que a atividade externa se tratava de um acampamento, de modo que "os Cadetes foram instruídos a montarem a barraca em que ficariam alojados" (Aluno 2). Uma das primeiras situações a incomodar os cadetes ocorreu quando um dos alunos, que tinha recebido uma determinação do major um dia antes para trocar o cadarço de elástico de seu coturno, não o fez. Na cultura militar, a ideia é que todos usem os mesmos equipamentos, de maneira uniforme (FOUCAULT, 1987). Com o descumprimento, ao desembarcarem, "o major cortou o cadarço do coturno do Cadete utilizando um facão. O cadete relatou ter se sentido constrangido devido ao episódio do corte do cadarço" (Aluno 3).

Ao amanhecer, os cadetes foram divididos em quatro equipes de maneira que "um grupo ficou na responsabilidade de realizar o local do "tchof", outro grupo deveria construir a latrina, o terceiro grupo realizou o local de acampamento, e o último grupo deveria fazer o local que seria a sala de aula durante a realização do acampamento" (Aluno 1). Entre as atividades iniciais, o "tchof" "seria uma alteração no curso de um córrego que havia ali próximo, para originar um (sic) espécie de represa, onde seriam realizadas algumas atividades de vivacidade; após a realização desse "tchof", mesmo a água do córrego sendo limpa, a água represada ficou turva" (Aluno 2). Com o decorrer das atividades, uma das que mais incomodaram os cadetes foi a refeição do primeiro dia, na hora do almoço, de modo que os relatos abaixo descrevem o acontecimento:

No almoço do primeiro dia foi distribuída uma quentinha para cada aluno e dado dois minutos para que pudessem comer; devido ao fato de não ter sido dado o fora de forma, a turma foi "forçada" a comerem (sic) com as mãos, pois não havia a possibilidade de conseguirem algum meio de fortuna para comer, em substituição aos talheres que não foram disponibilizados; após os dois minutos foi determinado que os cadetes colocassem o restante do alimento da quentinha em um único panelão; após colocarem o restante do alimento na panela, foi disponibilizado mais dois minutos para cada grupo continuar a comer; após cada grupo ter comido, foi disponibilizado mais cinco minutos para que toda a turma continuasse a comer, devendo levar a panela para o local que estavam alojados; após os cinco minutos era dado um silvo de apito para que os alunos informassem se haviam terminado de comer, caso não tivessem terminado deveriam realizar flexões no solo e voltar a comer; não se recorda quantos ciclos de cinco minutos houve. (Aluno 1).

A primeira refeição que tiveram, desde o momento que foram acordados, ocorreu aproximadamente por volta da hora do almoço, sendo disponibilizada uma quentinha para cada cadete e fornecido um tempo de 2 minutos para a realização da refeição, devendo ser feito com a mão, pois não foram distribuídos talheres; não foi disponibilizado tempo para realização de asseio e limpeza das mãos; a refeição foi realizada em pé; após esses 2 minutos o que restou da alimentação de todos os cadetes foi reunido em uma panela e após isso os cadetes foram divididos em grupos e cada grupo teve 2 minutos para ir à panela para continuarem a comer o restante da comida, utilizando as mãos, e todos os cadetes tiveram que comer; após todos os grupos irem até a panela ainda sobrou comida, então foi determinado aos cadetes que levasse (sic) a panela com o restante da comida para onde estava a barraca para conclusão da refeição, entretanto a cada 5 minutos eram dados silvos de apito e os cadetes tinham que realizar uma quantidade de flexões no solo e após as flexões eram 
disponibilizados mais 5 minutos para continuar a refeição, sendo realizado alguns ciclos dessa atividade até que toda a comida acabasse; eram alternados as flexões com o tempo que tinham para comer, sendo notório que em determinado momento já havia uma quantidade de areia dentro da comida. (Aluno 2).

Se recorda de uma das refeições, em que todas as quentinhas dos alunos foram reunidas em um recipiente, que não se recorda qual, e todos tiveram que comer juntos. (Aluno 3).

No primeiro dia, no período do almoço, foi disponibilizado algum tempo para o almoço, o qual estava em quentinhas, e após encerrar o tempo, o que restou da comida foi reunida (sic) em uma panela; tiveram que comer toda a comida e enquanto comiam realizavam flexões, intercalando com período que tinham (sic) para terminar de comer, até toda comida acabar; não tinham condições adequadas de higiene na hora do almoço. (Aluno 4).

Os longos trechos destacados dos depoimentos sobre a hora do almoço no acampamento revelam o descuido proposital por parte dos coordenadores com a falta de higiene para o manuseio da comida aliada ao desconforto e às atividades físicas empregadas como as flexões de braço que, em alternância com os momentos da alimentação, passou a deixá-la com "uma quantidade de areia"; vê-se com isso o caráter militar da atividade. Percebe-se nesse acontecimento a tentativa dos coordenadores de fazer com que os alunos tenham certa destreza para saberem lidar com o tempo e a forma de se alimentar própria de um evento bélico, no qual não há espaço para noções de higiene porque é a sobrevivência que importa.

O fortalecimento da concepção militar no acampamento (ALBUQUERQUE; MACHADO, 2001a) mostrouse por meio de agressões aos alunos, já que elementos como militarismo, masculinidade e rusticidade são parentes próximos, digamos assim. Casos como o das agressões e da morte do cadete do Exército Márcio Lapoente em 1990 (FRANÇA, 2020b), assim também como o dos cadetes que apanharam dos oficiais na JIM no CFO da Bahia demonstram a perpetuidade da violência institucional em cursos militares. No caso do acampamento BM em análise, não chegamos a tanto, mas tivemos situações como a descrita a seguir:

O major havia percebido que o cadete... havia deixado o material cair ao solo e ao observar que o referido cadete não havia se acusado, então se deslocou até onde estava o cadete e desferiu uma tapa em seu peito; enquanto se deslocava em direção ao cadete, o major proferia expressões como "isso não é atitude de homem", e após desferir a (sic) tapa contra o peito do cadete, o mesmo veio a cambalear, ficando sem reação. (Aluno 3).

O Major solicitou que o militar que havia errado a execução se acusasse (exercícios de polichinelo); que o cadete... se acusou, entretanto o Major informou que não havia sido ele; o Major então veio na direção do declarante desferindo três tapas fortes em seu peito, chegando a fazer o declarante se desequilibrar, mas não caiu ao solo; o Major então o segurou forte pela gola da gandola ${ }^{10}$, o sacolejando e fazendo força para cima, enquanto desferia algumas expressões agressivas, a exemplo de "seja homem", "assuma seus erros"; após isso, o declarante não manifestou nenhuma reação, ficando apático; o Major estava armado; na noite deste dia, diante do episódio vivenciado, não conseguiu dormir, mesmo sendo disponibilizado um tempo de descanso para a turma. (Aluno 1).

O clímax do acampamento ocorreu diante de uma situação inusitada. Devido ao acampamento ter sido organizado pelos coordenadores para ser uma surpresa e por conta do pouco tempo dado para os cadetes pegarem algum material necessário, nem todos os homens levaram lâminas de barbear ou barbeador

10 Parte superior do fardamento militar. 
para o acampamento, visto ser regulamentado o não uso de barba pelos homens de acordo com as regras militares. Esse fato foi o que obteve maior destaque nos depoimentos, pois diante da evidência de que não tinham lâminas nem barbeadores suficientes para todos e da recusa dos alunos em compartilhar os que tinham disponíveis: "a determinação foi que a turma entrasse no 'tchof' (água represada) e que só sairia de lá com a barba feita" (Aluno 1); "a determinação estava mantida, por parte da coordenação, e que o asseio pessoal deveria ser feito" (Aluno 4); "os termos adotados (em tom ríspido) por parte de ambos os oficiais (major e tenente) era que a imposição de se fazer a barba era uma ordem" (Aluno 3); "em face da postura da turma em não cumprir a determinação de fazer a barba, que imputaria necessariamente em compartilhar os barbeadores, vieram uma série de atividades punitivas à turma que tinham como objetivo principal mudar a postura dos alunos" (Aluno 2).

Como vimos até aqui, a obediência à autoridade é o requisito implícito, não diretamente divulgado pelos coordenadores, em situações como o acampamento militar (HUGGINS; HARITOS-FATOUROS; ZIMBARDO, 2006). Diante da ordem imposta, os cadetes, resignados, cumpriram a missão e compartilharam os barbeadores. O argumento dos coordenadores, como sempre centrado nas regras militares, previa que "diante da decisão de não cumprimento da determinação, a coordenação teve a percepção daquela atitude como sendo um motim [tipo de crime militar]" (Aluno 1). Mesmo pedindo desculpas à turma após o término do acampamento, pelo ocorrido na situação do uso coletivo dos barbeadores, ainda assim o tenente teria afirmado, com base em sua experiência pretérita no Exército, que "a situação não era absurdo, pois em momentos vivenciados anteriormente no Exército brasileiro [o tenente] já chegou a compartilhar um barbeador com 10 militares" (Aluno 3).

Como se vê ao final, são as práticas da cultura organizacional castrense o mote legitimador que fez do acampamento bombeiro militar analisado mais uma experiência a ser melhor compreendida da aplicabilidade da pedagogia militar em uma profissão que demanda um exercício de cunho eminentemente civil. Em meio aos paradoxos da profissão BM e seu hibridismo identitário, fica-nos mais um exemplo das dificuldades de alcançarmos uma democracia que proteja também profissionais que ainda em formação precisam ser reconhecidos não como máquinas treinadas para a guerra, mas como homens e mulheres que apenas buscam uma profissão como qualquer um de nós que convivemos em sociedade.

\section{CONSIDERAÇÕES FINAIS}

A denúncia feita ao Ministério Público contra os coordenadores do acampamento militar para os cadetes BM revela certo avanço contra o abuso cometido nessas atividades dirigidas sem considerações técnicas por meio da tradição puramente militar. O que percebemos é que a organização do acampamento pautouse em experiências prévias de um dos coordenadores que passou pelo mesmo processo no Exército e que acabou por adaptar situações para alunos bombeiros que exercerão uma função eminentemente de ordem civil. As situações vivenciadas pelos alunos deixam clara a presença de conteúdos autoritários e intimidatórios por parte dos coordenadores na forma de tratar os alunos durante os dias de acampamento, com a imposição de ordens absurdas e violentas como obrigá-los a compartilhar lâminas de barbear ou até mesmo se colocar no direito de violentar o corpo físico dos alunos com tapas e empurrões.

A falta de preparo profissional e comedimento das ações como um todo faz parte de um processo cultural absorvido da vida castrense e que chega à vida institucional dos BMs pela junção do modelo organizativo militar, da herança histórica desse modelo cultural naturalizado e pelo reforço de novos 
oficiais que ingressam na Corporação BM após passarem por experiências similares quando pertenciam ao quadro das Forças Armadas, em especial do Exército brasileiro. Enxergamos de forma positiva a denúncia contra as práticas que foram empregadas no acampamento BM, o que mostra, diferentemente de situações pretéritas nas quais dificilmente essas denúncias ocorriam, que tem se desenvolvido certa 'desnaturalização' desses procedimentos de ordem cultural. Tais condições de violência institucional no mundo militar são geralmente alimentadas pelo desejo à autoridade e pela insipiente concepção da aprendizagem pelo sofrimento, a qual é vazia de conteúdo. Ao contrário, talvez os CBMs consigam reverter tal quadro pedagógico se descobrirem o caminho da resolução de conflitos humanos a partir da criatividade e do senso de justiça e empatia desde a formação de seus futuros profissionais, legitimando uma proposição mais coerente ao lema dos bombeiros de 'vida alheia e riquezas salvar'.

\section{REFERÊNCIAS BIBLIOGRÁFICAS}

ALBUQUERQUE, C. L. de. Escola de bravos: cotidiano e currículo numa academia de polícia militar. Dissertação (Mestrado em Ciências Sociais) - Universidade Federal da Bahia, 1999.

ALBUQUERQUE, C. L. de; MACHADO, E. P. O currículo da selva: ensino, militarismo e ethos guerreiro nas academias brasileiras de polícia. Capítulo Criminológico, v. 29, n. 4, p. 5-33, dez. 2001a. Disponível em: http://www.corteidh.or.cr/tablas/r06732.pdf. Acesso em: 18 jul. 2017.

ALBUQUERQUE, C. L. de; MACHADO, E. P. Sob o signo de Marte: modernização, ensino e ritos da instituição policial militar. Sociologias, Porto Alegre, ano 3, n. 5, p. 214-237, jan./jun. 2001b. Disponível em:http:// www.scielo.br/scielo.php?pid=S1517-45222001000100010\&script=sci_abstract\&tlng=pt . Acesso em: 1 mar. 2020.

ALBUQUeRQuE, C. L. de; MACHADO, E. P. O batizado dos recrutas: trote, socialização acadêmica e resistência ao novo ensino policial brasileiro. Capítulo Criminológico, v. 31, n. 2, p. 101-127, abr./jun. 2003. Disponível em: http://produccioncientificaluz.org/index.php/capitulo/article/viewFile/5049/5040. Acesso em: 17 jul. 2017.

ALMEIDA JÚNIOR, A. R. de. Anatomia do trote universitário. São Paulo: Hucitec, 2016.

ALVITO, M. Memórias de "bicho". Revista do Arquivo Geral da Cidade do Rio de Janeiro, n. 7, p. 155-173, 2013. Disponível em: http://wpro.rio.rj.gov.br/revistaagcrj/wp-content/uploads/2016/11/e07_a5.pdf. Acesso em: 14 abr. 2019.

BERTAUD, J. P. O exército e o brevê de virilidade. In: CORBIN, A.; COURTINE, J. J.; VIGARELLO, G. (Orgs.). História da virilidade: o triunfo da virilidade: o século XIX. Petrópolis/RJ: Vozes, 2013.

BRASIL. Emenda Constitucional N 18, de 5 de fevereiro de 1998. Dispõe sobre o regime constitucional dos militares. Disponível em: http://www.planalto.gov.br/ccivil_03/constituicao/emendas/emc/emc18. htm. Acesso em: 1 set. 2017.

CASTRO, C. In corpore sano - os militares e a introdução da educação física no Brasil. Antropolítica, Niterói/RJ, n. 2, p. 61-78, 1 sem. 1997.

CASTRO, C. O espírito militar: um antropólogo na caserna. Rio de Janeiro: Jorge Zahar, 2004. 
DUARTE-PLON, L. A tortura como arma de guerra - da Argélia ao Brasil: como os militares franceses exportaram os esquadrões da morte e o terrorismo de Estado. Rio de Janeiro: Civilização Brasileira, 2016.

ELIAS, N. O processo civilizador: uma história dos costumes. v. 1. Rio de Janeiro: Jorge Zahar, 1994.

FERNANDES, E. Veja vídeos - Aluno tinha descontrole emocional, diz Ledur. Gazeta Digital, Judiciário, Caso Rodrigo Claro, 12 mar. 2020. Disponível em: https://www.gazetadigital.com.br/editorias/judiciario/ veja-vdeos-aluno-tinha-descontrole-emocional-diz-ledur/610126. Acesso em: 10 jun. 2020.

FERNANDES, H. R. Política e segurança. São Paulo: Alfa Ômega, 1973.

FOUCAULT, M. Vigiar e punir: história das violências nas prisões. Rio de Janeiro: Vozes, 1987.

FRANÇA, F. G. de. Disciplinamento e humanização: a formação policial militar e os novos paradigmas educacionais de controle e vigilância. Dissertação (Mestrado em Sociologia) - Universidade Federal da Paraíba, João Pessoa, 2012.

FRANÇA, F. G. de. Desvio, moralidade e militarismo: um olhar sobre a formação policial militar na Paraíba. Revista Brasileira de Sociologia da Emoção, João Pessoa, v. 12, n. 36, p. 803-818, dez. 2013. Disponível em: http://www.cchla.ufpb.br/rbse/FrancaDos.pdf. Acesso em: 14 fev. 2020.

FRANÇA, F. G. de. Os "soldados do fogo": um estudo sobre violência institucional na profissão bombeiro militar. Revista Brasileira de Ciências Criminais, São Paulo, ano 26, v. 149, p. 419-453, nov. 2018.

FRANÇA, F. G. de. "O Soldado é algo que se fabrica": notas etnográficas sobre um curso de formação policial militar. Revista Tomo, Sergipe, n. 34, p. 359-392, jan./jun. 2019. Disponível em: https://seer.ufs.br/ index.php/tomo/article/view/10378. Acesso em: 10 jun. 2020.

FRANÇA, F. G. de. “Nunca serão!": o Bope e a caveira totêmica. João Pessoa: Ideia, 2020a.

FRANÇA, F. G. de. O caso Márcio Lapoente e a questão dos direitos humanos nas casernas militares. Confluências, v. 22, n. 1, p. 71-88, abr./jul. 2020b. Disponível em: https://periodicos.uff.br/confluencias/ article/view/40627. Acesso em: 10 jun. 2020.

FRANÇA, F. G. de; GOMES, J. L. de F. "Se não aguentar, corra!": Um estudo sobre a pedagogia do sofrimento em um curso policial militar. Revista Brasileira de Segurança Pública, São Paulo, v. 9, n. 2, p. 142-159, ago./set. 2015. Disponível em: http://www.revista.forumseguranca.org.br/index.php/rbsp/ article/viewFile/506/213. Acesso em: 14 jul. 2017.

FRANÇA, F. G. de; RIBEIRO, L. R. "Um bombeiro pede socorro!": socialização, treinamento e sofrimento na formação do bombeiro militar. Sociologias, Porto Alegre, ano 21, n. 51, p. 212-241, maio/ago. 2019. Disponível em: https://seer.ufrgs.br/sociologias/article/view/84492. Acesso em: 14 fev. 2020.

GOFFMAN, E. Manicômios, prisões e conventos. São Paulo: Perspectiva, 2007.

GOMIDE, R. O infiltrado: um repórter dentro da polícia que mais mata e mais morre no Brasil. Versão e-book, 2018.

HUGGINS, M. K.; HARITOS-FATOUROS, M.; ZIMBARDO, P. G. Operários da violência: policiais torturadores e assassinos reconstroem as atrocidades brasileiras. Brasília: Editora UnB, 2006. 
LEAL, G. R. Currículo cultural: Uma autoetnografia na Academia de Polícia Militar Costa Verde. Dissertação (Mestrado em Educação) - Instituto de Educação, Universidade Federal de Mato Grosso, Cuiabá/MT, 2011.

LEIRNER, P. de C. Meia-volta volver: um estudo antropológico sobre a hierarquia militar. Rio de Janeiro: Editora FGV, 1997.

MARQUES, J. P. Escolas militares do exército: a formação, seus mitos e ritos (1889-1931). Tese (Doutorado em Educação Brasileira) - Faculdade de Educação, Universidade Federal do Ceará, Fortaleza/CE, 2014.

SILVA, R. R. da. Entre a caserna e a rua: o dilema do "pato" - uma análise antropológica da instituição policial militar a partir da Academia de Polícia Militar D. João VI. Niterói: Editora da UFF, 2011.

TURNER, V. O processo ritual: estrutura e antiestrutura. Petrópolis: Vozes, 2013.

VAN GENNEP, A. Ritos de passagem: Estudo sistemático dos ritos da porta e da soleira, da hospitalidade, da adoção, gravidez e parto, nascimento, infância, puberdade, iniciação, ordenação, noivado, casamento, funerais, estações, etc. Petrópolis: Vozes, 2011. 
A pedagogia do sofrimento em um acampamento bombeiro militar

Fábio Gomes de França

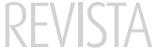

BRASILEIRA

"SEGURANCA PÚBLICA

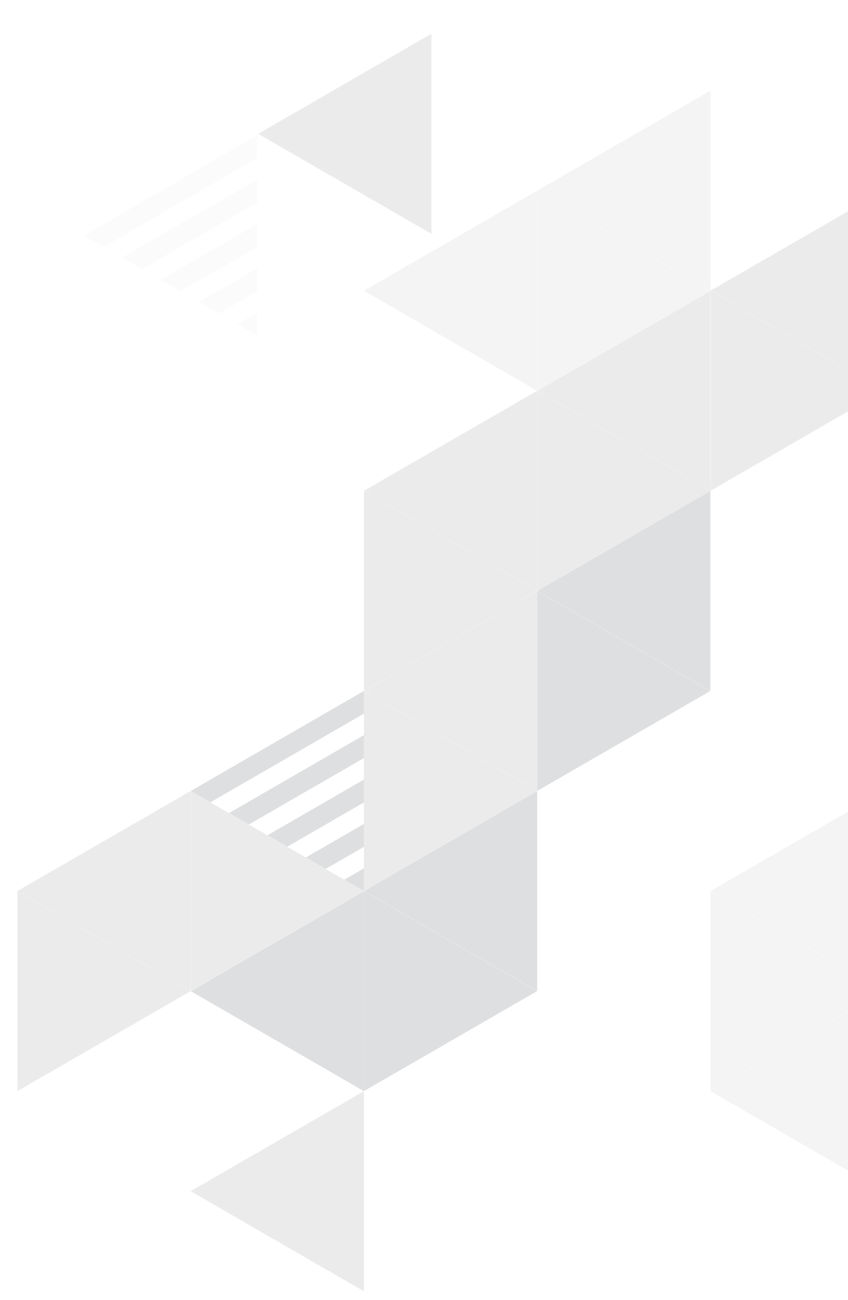

